\title{
Manufacture and Sensor's Characterization for Optimizing the Manufacture of Resistance Sensors Based on Tea with Natural Sugar and Artificial Sugar
}

\author{
Cindy Septiani S*, Defanny, Frida Agung Rakhmadi \\ Physics Department, Faculty of Science and Technology, UIN Sunan Kalijaga \\ Email*: cindyseptianis@gmail.com
}

\begin{abstract}
This research aims to identify sensors. This research was carried out through 3 stages, namely: designing resistance sensors, making resistance sensors, testing resistance sensors. The sensor sheceme by using software Fritzing. The tools used in making these sensors include Power and solder, for materials used are plain $\mathrm{PCB}, 2.2 \mathrm{~K} \Omega$ resistors, copper wire, paper, pens, rulers, and materials for testing are tea, natural sugar and artificial sugar. Sensor testing is performed in data collection by measuring voltage. Because the data generated is in the form of voltage. By doing 2 variations of the volume of $50 \mathrm{ml}$ and $100 \mathrm{ml}$ which is done 5 times with each volume repetition. The data obtained is then processed by calculating the mean and its uncertainty. The results of this research provide information that the natural sugar tea voltage for $50 \mathrm{ml}$ volume $(0.958 \pm 0.1916) 80 \%$ repeatability. And for $100 \mathrm{ml}$ volume $(0.884 \pm$ $0.1768)$ the compatibility is $80 \%$. While the artificial sugar tea voltage for $50 \mathrm{ml}$ volume $(1.488 \pm 0.2976) 80 \%$ compatibility and for $100 \mathrm{ml}$ volume $(1.484 \pm 0.2968) 80 \%$ repeability. From the data obtained, both can be seen to have different voltage values and the same compatibility value, which is $80 \%$. Because the resulting repeatability does not reach national standards, this sensor cannot be used.
\end{abstract}

Keywords: characacterization, resistance sensors, tea natural sugar, artificial sugar

\section{INTRODUCTION}

Sugar is a simple carbohydrate that can dissolve in water and directly absorbed by the body to be converted into energy. Sugar is an ingredient that is often used by people to sweeten food and drinks. Sugar is now many different kinds, not only natural sugar, there are also artificial sugars. Examples of natural sugars that are widely circulating in the market are granulated sugar and examples of artificial sugars on the market, saccharin. Natural sugar is safer to consume than artificial sugar.

The American Heart Association recommends limiting additional sugar to 6 teaspoons ( 25 grams) per day for women and 9 teaspoons (36 g) per day for men. Nutritionist Samantha Cassetty, RD, says 75 percent of packaged foods, including cereals, granola bars, yogurt with even fruit, bread and flavored flavors, contain added sugar. This is what makes a person excessive in consuming sugar. If added sugar is used for a long time it will cause metabolic disorders, play a role in weight problems, diabetes, increase the risk of heart disease, and tooth decay. Dr. Ervina Hasti said too much consumption of artificial sugar can have a direct impact such as sugar addiction or sugar addiction, spikes in blood sugar and fast feeling hungry (craving), if it goes on continuously it will cause various health problems such as obesity, heart problems and cholesterol.

In this research, the authors used a type of granulated sugar as a natural sample. Granulated sugar is a simple carbohydrate made from sugar cane juice. Granulated sugar is usually used in daily life, both in the industrial and household world.

\section{MATERIALS AND METHODS}

This research will be carried out in three phases, namely: designed a resistance sensor, made a resistance sensor, and tested a resistance sensor. The three phases will be explained as follows. The first phase in terms of designing is making a resistance sensors circuit, making a resistance sensors circuit using the Fritzing software. Fritzing is used because fritzing is software that is easily applied and used in making electronics learning easily. This stage will later produce a resistance sensors design. For materials used in this phase namely; paper, pens, and rulers. The second phase makes a resistance sensor. The target produced in this stage is the production of a resistance sensors. With the material used in this phase namely; Plain PCB, $2.2 \mathrm{~K} \Omega$ resistor, copper wire. The third phase is testing the resistance sensors. The target in achieving this step is to get the correct test results and be able to understand the characteristics of the resistance sensors that have been made and tested. Tools and materials used in this stage are; power supply $(5 \mathrm{~V})$ and sample trials. Test samples used are tea samples using natural sugar and tea using artificial sugar. By using a varied volume of $50 \mathrm{ml}$ and $100 \mathrm{ml}$. Retrieval of data is taken by using a resistance sensors and the output is in the form of voltage. With data retrieval as much as 5 times. After the data is generated, a data analysis is 
performed to characterize the resistance sensor. To get the average value use the following equation:

$$
\bar{V}=\frac{\sum V i}{N}
$$

Thus $\boldsymbol{V}$ namely the average resistance value and $\boldsymbol{N}$ is the number of measurements. After obtaining the average value of resistance continued by determining the uncertainty value of the experiment using the equation (Morris, 2014).

$$
\Delta V=\frac{1}{N} \sqrt{\frac{N \sum V i^{2}-\left(\sum V i\right)^{2}}{N-1}}
$$

To get the Repeatability value, use the following equation:

$$
\text { Repeatability }=100 \%-\delta
$$

\section{RESULTS AND DISCUSSION}

The results of sensors design are made using the fritzing application
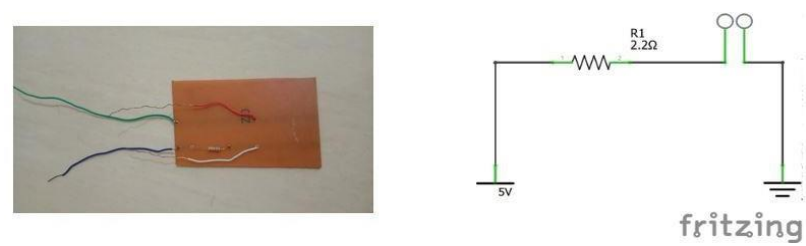

Figure 1. The results of sensors design and sensor manufacturing.

This resistance sensor uses a voltage of $5 \mathrm{~V}$. This resistance sensor uses only one resistor that is equal to $2.2 \mathrm{~K} \Omega$. 71 When there are two copper wires $3 \mathrm{~cm}$ apart. The wire will be dipped into the sample to the bottom of the measuring cup then the resistance will be read by the sensor. The sample in this research serves as an object in characterizing the sensors that have been made. The results of data analysis that have been carried out on different samples produced average voltage on the sample with variations and its uncertainty. For tea that uses natural sugars, the zero offset linear transfer function value when the input is 0 or not given a voltage, the output read is $1,032 \mathrm{~V}$ and for the sensitivity value is $-0.00148 \mathrm{~V} / \mathrm{ml}$. As for the tea that use artificial sugars linear transfer function zero value offset $1.492 \mathrm{~V}$ and for the sensitivity value $-0.00008 \mathrm{~V} / \mathrm{ml}$. The resulting compatibility is also quite high. The resulting linier correlation coefficient is quite high at $95,70 \%$ and $95,40 \%$. So this sensor can be used because it produces good value.

Table 1. Results of Resistance Sensor characterization in tea samples using natural sugars.

\begin{tabular}{l|l}
\hline Volume $(\mathrm{ml})$ & Voltage (Volt) \\
\hline 50 & $0,958 \pm 0,1916$ \\
100 & $0,884 \pm 0,1768$ \\
\hline
\end{tabular}

Table 2. Results of Resistance Sensor characterization in tea samples using artificial sugars.

\begin{tabular}{l|l}
\hline Volume $(\mathrm{ml})$ & Voltage $($ Volt $)$ \\
\hline 50 & $1,488 \pm 0,2976$ \\
100 & $1,484 \pm 0,2968$ \\
\hline
\end{tabular}

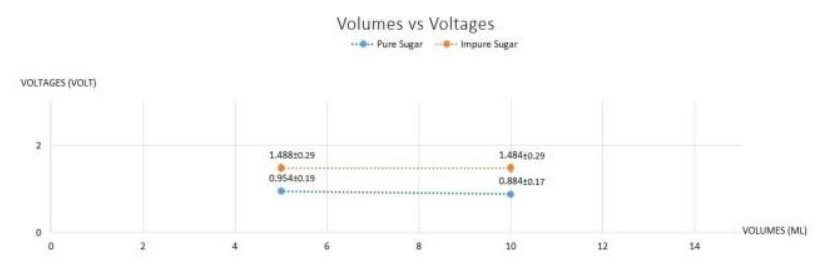

Figure 2. Graphic Volume vs Voltage.

\section{CONCLUSION}

The results of this research provide information that the natural sugar tea voltage for $50 \mathrm{ml}$ volume $(0.958 \pm$ $0.1916) 80 \%$ repeatability. And for $100 \mathrm{ml}$ volume $(0.884$ $\pm 0.1768)$ the compatibility is $80 \%$. While the artificial sugar tea voltage for $50 \mathrm{ml}$ volume $(1.488 \pm 0.2976) 80 \%$ compatibility and for $100 \mathrm{ml}$ volume $(1.484 \pm 0.2968)$ $80 \%$ repeability. From the data obtained, both can be seen to have different voltage values and the same compatibility value, which is $80 \%$. Because the resulting repeatability does not reach national standards, this sensor cannot be used.

\section{REFERENCES}

Https://www.haibunda.com/moms-life/20190802113324-7651190/fakta-tentang-gula-buatan-yang-penting-bunda ketahui

Morris, Alan S. Langari, Reza. 1948. Measurement and Instrumentation Theory and application, USA. 